\title{
Recent advances in management of bladder overactivity
}

\section{Ariana L Smith* and Alan J Wein}

\author{
Address: Division of Urology, University of Pennsylvania, School of Medicine, 3400 Spruce Street, 9 Penn Tower, Philadelphia, PA 19104, USA \\ *Corresponding author: Ariana L Smith (ariana.smith@uphs.upenn.edu) \\ Fl000 Medicine Reports 2010, 2:9 (doi:10.3410/M2-9)
}

The electronic version of this article is the complete one and can be found at: http://fl000.com/reports/medicine/content/2/9

\begin{abstract}
Pharmacologic therapies, primarily antimuscarinic agents, have been the mainstay of treatment for overactive bladder. These drugs produce variable efficacy, a moderate rate of side effects, and rare occurrences of cure. The search for newer and better formulations and derivatives of this class of medication as well as novel therapies is ongoing and primarily fueled by the high prevalence of overactive bladder and the tremendous number of health care dollars spent on current therapy. Surgical options for overactive bladder have evolved slowly and are currently reserved for medical treatment failures and drug intolerance. This article will highlight the new drugs and therapies brought into clinical use for the treatment of overactive bladder over the last few years as well as a promising new agent in the advanced stages of development.
\end{abstract}

\section{Introduction and context}

Overactive bladder (OAB) affects between $8.0-13.9 \%$ of the population in Western nations [1]. This variation in prevalence is thought to be due primarily to differences in the definition of $\mathrm{OAB}$ used across different study populations. The International Continence Society has defined $\mathrm{OAB}$ as 'urgency, with or without urge incontinence, usually with frequency and nocturia' [2] in attempts to standardize reporting of this highly prevalent and bothersome condition. The drugs most commonly prescribed for the treatment of $\mathrm{OAB}$ are the antimuscarinics; these drugs are proven efficacious and safe and are the mainstay of treatment for $\mathrm{OAB}$ [3]. These agents produce symptomatic improvement by reducing urgency and therefore urge urinary incontinence (UI) and frequency, decreasing detrusor overactivity and increasing bladder capacity [4]. There are several drugs available for use today, with some variability based on country of residence. As newer antimuscarinic agents have become available, some progress has been made in maximizing therapeutic efficacy while minimizing bothersome side effects; however, a large number of patients remain dissatisfied with the mix of efficacy and tolerability and discontinue therapy. Nevertheless, most physicians prescribe a trial of antimuscarinic therapy and behavioral modification in patients with bothersome $\mathrm{OAB}$, and if it is not effective, a second trial using a different drug or formulation is often instituted. When these drugs fail, the side effects become intolerable, or the category of drug is contraindicated, physicians have limited therapeutic options, including off-label use of other categories of drug or more invasive treatment options such as neuromodulatory agents or devices.

With recent advances in the science of $\mathrm{OAB}$, it has become clear that the functioning and malfunctioning of the urinary bladder are much more complex than previously appreciated and that other targets besides the muscarinic receptors should be addressed. The continuous evolution and development of innovative agents for the treatment of $\mathrm{OAB}$ stem from the fact that the ideal agent - one that is lower urinary tract (LUT)-selective, easily administered, and relatively inexpensive - has yet to be found. This search continues and therapies with different mechanisms of action are currently being studied with some promise.

\section{Recent advances}

Several new therapies have been added to the armamentarium of treatment options for $\mathrm{OAB}$ over the last couple 
of years. These include oxybutynin (OXY) topical gel, fesoterodine, trospium extended release (ER), continued development of novel $\beta_{3}$ adrenergic receptor (AR) agonists, off-label use of phosphodiesterase (PDE) inhibitors, off-label use of intradetrusor botulinum toxin (BTX), and advances in neuromodulation. Some of these additions represent new drugs approved specifically for $\mathrm{OAB}$ and others represent new or offlabel uses of previously approved therapies. Additionally, advances in the understanding of $\mathrm{OAB}$ through basic science research have not only opened the door to new categories of drug therapy but also enhanced our utilization of available antimuscarinics for the treatment of $\mathrm{OAB}$ in the setting of bladder outlet obstruction, an often concomitant disease process. Together, these recent advances have had a modest impact on clinical practice.

\section{Oxybutynin topical gel}

OXY topical gel is a new transdermal formulation that is applied once daily to the abdomen, thigh, shoulder, or upper arm area [5]. The 1 gram application dose delivers approximately $4 \mathrm{mg}$ of drug to the circulation with stable plasma concentrations. In a multicenter randomized control trial (RCT), 789 patients (89\% women) with urge-predominant UI were assigned to OXY gel or placebo once daily for 12 weeks. The mean number of urge UI episodes, as recorded by 3-day voiding diary, was reduced by 3.0 episodes per day versus 2.5 in the placebo arm $(P<0.0001)$. Urinary frequency decreased by 2.7 episodes per day and voided volume increased by $21 \mathrm{~mL}$ (versus 2.0 episodes $[P=0.0017]$ and $3.8 \mathrm{~mL}[P=$ $0.0018]$, respectively, in the placebo group). Dry mouth was reported in $6.9 \%$ of the treatment group versus $2.8 \%$ of the placebo group. Skin reaction at the application site was reported in $5.4 \%$ of the treatment group versus $1.0 \%$ in the placebo arm. It is felt that improved skin tolerability of the gel over the OXY transdermal patch delivery system is secondary to lack of adhesive and skin occlusion. The gel dries rapidly upon application and leaves no residue; person-to-person transference via skin contact is largely eliminated if clothing is worn over the application site. The evolution of the transdermal gel allows greater patient tolerability and improved compliance. Further data are needed to assess whether the decreased rate of side effects is at the expense of diminished efficacy. This would require a head-to-head trial with another antimuscarinic drug, a type of trial that occurs only rarely, creating a major challenge in evaluating the comparative efficacies of these agents.

\section{Fesoterodine}

Fesoterodine is a new oral antimuscarinic drug that is metabolized rapidly and extensively to 5-hydroxymethyl tolterodine (5-HMT), the same active metabolite of tolterodine [6]. 5-HMT is metabolized in the liver, but there is significant renal excretion without additional metabolism, raising the possibility that 5-HMT could also work from the luminal side of the bladder [7]. Fesoterodine is indicated for the treatment of $\mathrm{OAB}$ at doses of 4 and $8 \mathrm{mg}$ daily. In a multicenter, doubleblind, double-dummy RCT with tolterodine ER, 1132 patients were enrolled and received treatment [6]. The trial showed that both the 4 and $8 \mathrm{mg}$ doses of fesoterodine were effective in improving symptoms of $\mathrm{OAB}$, with the $8 \mathrm{mg}$ dose having a greater effect at the expense of a higher rate of dry mouth. There appears to be little difference between fesoterodine $4 \mathrm{mg}$ and tolterodine ER. Only one subject from the fesoterodine $8 \mathrm{mg}$ group and one subject from the tolterodine ER group withdrew from the study due to dry mouth. The dose-response relationship was confirmed in another study that pooled data from two phase III RCTs [8]. Fesoterodine $8 \mathrm{mg}$ performed better than the $4 \mathrm{mg}$ dose in improving urgency and urge UI as recorded by 3-day bladder diary, offering the possibility of dose titration. Further studies are needed to determine whether patients prefer the more efficacious $8 \mathrm{mg}$ dose despite the added side effects.

\section{Trospium extended release}

The development of a once-daily formulation of trospium chloride was a necessary step to maintain its place in the competitive antimuscarinic drug market. In addition to convenience and improved compliance, the ER deliver system was felt to lower maximum plasma concentration levels of the drug and thus decrease the incidence of side effects. Phase III data confirmed the efficacy of the ER formulation in reducing the number of voids per day and urge UI episodes per day [9]. Additionally, improvements in urgency severity, volume voided, and urgency voids per day were seen. Dry mouth incidence was $8.7 \%$ in the trospium ER group versus 3\% in the placebo group; $8.7 \%$ is the lowest reported rate of dry mouth for this class of drug. Subsequent authors have confirmed the improved tolerability profile of trospium ER; constipation rates in this study were 7.5\% versus $1.8 \%$ in placebo [10]. MacDiarmid et al. [11] tabulated an average dry mouth incidence of $20.1 \%$ with trospium immediate release (IR) versus $10.7 \%$ with trospium ER and average constipation rates of $9.6 \%$ with trospium IR and 8.5\% with trospium ER.

\section{$\boldsymbol{\beta}_{3}$ adrenergic receptor agonists}

It has yet to be proven whether the sympathetic nervous system plays an active role in the filling/storage phase of the bladder in humans; however, the presence of $\beta$ ARs in human bladder muscle prompted many attempts to increase bladder capacity with $\beta$ adrenergic stimulation. 
Development of $\beta_{3}$ agonists came after the discovery that the human detrusor muscle contains a predominance of $\beta_{3}$ subtype ARs (97\%) compared with $\beta_{1}(1.5 \%)$ and $\beta_{2}$ $(1.4 \%)[12,13]$. Detrusor muscle relaxation has been found to result from $\beta_{3}$ AR agonist therapy in animal models; furthermore, the effect appears to result in increased bladder capacity with no change in micturition pressure or residual urine volume $[14,15]$. Several selective $\beta_{3}$ agonists are being evaluated in clinical trials for the treatment of OAB. Acetanilide (YM178) was evaluated in patients with $\mathrm{OAB}$ in an RCT versus tolterodine and placebo [16]. The treatment group experienced a significant reduction in micturition frequency, incontinence episodes, and urgency symptoms as well as an increase in volume voided. The drug was well tolerated in this study, with the most common side effects being headache and gastrointestinal effects. Further studies are under way to determine whether this class of drugs is equivalent or superior to currently available alternatives in terms of efficacy, tolerability, and safety. These drugs are currently in the advanced stages of development.

\section{Phosphodiesterase inhibitors}

PDE inhibitors (sildenafil, tadalafil, and vardenafil) are generally prescribed for the treatment of erectile dysfunction (ED) and were found incidentally to improve LUT symptoms in men [17]. LUT smooth muscle undergoes relaxation in the presence of cyclic adenosine monophosphate (CAMP) and cyclic guanosine monophosphate (cGMP), and PDE inhibitors block the degradation of CAMP and CGMP, resulting in greater intracellular concentrations [18]. This class of drug is not currently approved for the treatment of OAB or other LUT symptoms and its use for this indication is off-label. In an RCT evaluating the effects of sildenafil on ED and LUT symptoms in 189 men, significant improvements in International Prostate Symptom Score (IPSS) and healthrelated quality of life (HRQoL) were seen [19]. In the first RCT looking at sildenafil and voiding dysfunction in women, no significant differences were seen in patients with complete retention, partial retention, or obstructed voiding [20]. An RCT comparing tadalafil with placebo in 281 men with ED and LUT symptoms produced clinically meaningful and significant symptomatic improvement in LUT symptoms [21]. In another RCT, vardenafil $10 \mathrm{mg}$ twice daily in men with ED and LUT symptoms showed a significant improvement in IPSS and HRQoL [22]. The PDE-1 inhibitor vinpocetine was evaluated in a multicenter, double-blind RCT in patients with urgency and urge UI with urodynamically documented detrusor overactivity who failed antimuscarinic therapy [23]. The patients received either vinpocetine
$20 \mathrm{mg}$ three times daily or placebo. The results showed a significant reduction in micturition frequency in men; however, the remainder of assessed outcomes showed a trend toward improvement without reaching significance. The lack of side effects in this study indicates that the dose delivered may have been too low. While largescale studies in women using PDE inhibitors for OAB have yet to be done, the early data in men suggest a possible role in the treatment of bladder diseases. The mechanism of action to produce this beneficial effect in $\mathrm{OAB}$ remains unknown at this time.

\section{Botulinum toxin}

BTX (Botox ${ }^{\circledR}$; Allergan, Inc., Irvine, CA, USA) is a neurotoxin produced by Clostridium botulinum and is a potent presynaptic inhibitor of acetylcholine release at the neuromuscular junction. It is applied directly by cystoscopic injection into the detrusor muscle, producing a chemical denervation that is reversible after approximately 6 months. The mode of administration allows high concentrations of the agent to reach the bladder tissue without systemic administration and resultant unsuitable levels in other organs. BTX is not approved for the treatment of $\mathrm{OAB}$ but is now widely used in patients who are refractory to conventional antimuscarinic therapy or who do not tolerate it due to systemic side effects.

The dose and injection protocol for BTX has not been universally agreed upon and several variations exist. In the initial description for the treatment of neurogenic $\mathrm{OAB}, 300$ units (U) of BTX-A was diluted in normal saline to a concentration of $10 \mathrm{U} / \mathrm{mL}$. Under direct cystoscopic visualization using a $6 \mathrm{~F}$ injection needle, 30 injections of $1 \mathrm{~mL}$ each were administered to the bladder wall in 30 different locations above the trigone [24]. Since that description, several other authors have described varying doses, dilutions, numbers of sites, and locations (trigone, suburothelial space, and so on). The onset of BTX-A effects is seen within the first 2 weeks after injection [25]. Urgency, nocturia, and frequency have been shown to improve as early as 2 days after injection [26]. The reported duration of BTX-A following the first injection was 6-9 months [25], and duration of effect along with beneficial clinical effect after subsequent injections is maintained [27].

In a double-blind RCT including 34 patients with $\mathrm{OAB}$ refractory to antimuscarinics, $200 \mathrm{U}$ of BTX-A was studied [28]. Significant improvements in maximum cystometric capacity, frequency, and UI episodes were seen at 4 and 12 weeks. Despite clinical improvement, 6 patients $(37.5 \%)$ required clean intermittent catheterization (CIC) to empty their bladder. In another RCT, 
28 women with refractory OAB received BTX-A 200 U and 15 women received placebo [29]. Approximately $60 \%$ of the women who received BTX-A reported a clinical response with a mean duration of response of 373 days (compared with 62 days or less for placebo). Post-void residual (PVR) urine was increased in $43 \%$ of women in the treatment group and urinary tract infections occurred in $75 \%$ of these women. The duration of retention following the first injection was approximately 2 months; however, following repeat injection, this duration increased to 5 months.

Given the degree of voiding dysfunction seen after BTX injection in patients with $\mathrm{OAB}$, dose reduction studies looking at $100 \mathrm{U}$ have been done. In a prospective, non-randomized study including 100 men and women, $100 \mathrm{U}$ of BTX-A was injected in 30 locations [30]. At 4and 12-week follow-up, $88 \%$ of patients showed significant improvement in bladder function in regard to subjective symptoms, urodynamic parameters, and HRQoL. There were four cases of urinary retention.

BTX appears to be a promising therapy in the treatment of neurogenic and idiopathic OAB. Further studies are needed to determine optimum dosages, locations, and methods of injection. The case for usage in neurogenic $\mathrm{OAB}$ patients on $\mathrm{CIC}$ who leak between catheterizations seems clearer than in patients with idiopathic $\mathrm{OAB}$, in whom the PVR issue has yet to be clarified.

\section{Neuromodulation}

Sacral neuromodulation (SNM) is well established as a treatment modality for refractory urgency, frequency, urge UI, and idiopathic urinary retention. The mechanism of action remains unknown but theories include modulation of spinal cord reflexes and brain networks primarily via somatic sensory afferent fibers [31]. Success rates vary based on the technique used for placement (with the two-stage approach having greater efficacy than the percutaneous nerve evaluation) and the indication for intervention (with slightly higher efficacy found among patients with idiopathic urinary retention compared with urgency/frequency and urge UI) [32]. Evolution in our understanding of neuromodulation has allowed expanded indications for treatment and alternative approaches for nerve stimulation. When unilateral SNM fails, options for salvage include contralateral lead placement with the potential for bilateral stimulation or utilization of an alternative approach to stimulation via the tibial or pudendal nerves. In addition, previously excluded patients such as those with neurologic diseases like multiple sclerosis or Parkinson's disease and patients with incomplete spinal cord injuries have undergone successful treatment using neuromodulation and are beginning to be recognized as potential candidates $[33,34]$.

One alternative approach is percutaneous tibial nerve stimulation (PTNS), a non-invasive way of modulating pelvic reflexes via projections from the posterior tibial nerve [35]. Urgent ${ }^{\circledR}$ PC (Uroplasty, Inc., Minnetonka, $\mathrm{MN}$, USA) is an office procedure approved by the US Food and Drug Administration and is used to deliver stimulation to the posterior tibial nerve using a 34-gauge needle electrode placed slightly cephalad to the medial malleolus. The recommended course of treatment is 12 weekly sessions of 30 minutes each [36]. The Overactive Bladder Innovative Therapy (OrBIT) trial was a randomized, multicenter, control trial that compared PTNS with tolterodine ER; $79.5 \%$ of patients in the PTNS arm reported cure or improvement in symptoms compared with $54.8 \%$ of the tolterodine group as measured by the global response assessment $(P=0.01)$ [35]. Objective measures, including urinary frequency, urge UI episodes, urge severity, nighttime voids, and volume voided, showed similar improvement in the two groups. The authors concluded that PTNS was a 'clinically significant treatment alternative for $\mathrm{OAB}^{\prime}$.

A second alternative approach is stimulation of the pudendal nerve within the Alcock canal by means of neurophysiological guidance [37]. This is a logical alternative to direct sacral root stimulations since many of the sensory afferent fibers of the sacral nerves originate in the pudendal nerve, which in fact innervates the pelvic organs [38]. Peters et al. [38] reported a 71.4\% response rate ( $>50 \%$ improvement) in a mixed population of patients with $\mathrm{OAB}$, painful bladder syndrome, neurologic voiding dysfunction, and non-obstructive urinary retention, of whom $52 \%$ had failed prior sacral stimulation [38]. In a previous comparative study, 30 patients underwent simultaneous sacral and pudendal lead placement with subsequent blinded and randomized stimulation of each electrode [39]. In 79.2\% of patients, the pudendal lead was chosen as superior, with a $63 \%$ reduction in symptoms (versus $46 \%$ reduction with sacral stimulation, $P=0.02$ ).

\section{Antimuscarinics and urinary retention}

Advances in the understanding of the mechanisms of action of antimuscarinic agents and the pathophysiology of OAB through basic science research have enhanced our utilization of antimuscarinics for the treatment of $\mathrm{OAB}$ in the setting of bladder outlet obstruction, an often concomitant disease process. The use of these drugs in this setting was previously feared due to the theoretical risk of urinary retention, and in the past there was universal concern regarding the risk of acute retention 
when prescribing antimuscarinic drugs. However, as Andersson and Wein [40] and Andersson et al. [41] propose, these drugs are usually competitive antagonists, implying that when there is massive release of acetylcholine during voiding, the relative effect of the drug should be diminished. If this did not occur, urinary retention would result from the inability of the bladder to contract. In fact, at high doses, urinary retention can occur but this is uncommon at the doses typically prescribed for $\mathrm{OAB}$ [40]. Our current understanding is that the dose range used for beneficial effects in $\mathrm{OAB}$ is much lower than that needed to produce a significant reduction in the voiding contraction. Monitoring PVRs in patients with prostatic enlargement or incomplete bladder emptying is still recommended; however, these diagnoses should not be considered absolute contraindications to the use of antimuscarinics.

\section{Implications for clinical practice}

Pharmacologic therapies, primarily antimuscarinic agents, have been the mainstay of treatment for OAB. For many patients, the side effects of oral administration are intolerable, producing a clear demand for an agent that bypasses first-pass metabolism in the liver. The new OXY gel serves this purpose without the local skin effects seen with the previously approved OXY patch. Fesoterodine offers another oral option to the long list of oral agents available. Its uniqueness lies in its optimum biopharmaceutics profile with decreased lipophilicity and permeability across biological interfaces, producing at least a theoretically lower incidence of side effects [42]. Additionally, there is less variability in the pharmacokinetics of this agent due to its metabolism by ubiquitous non-specific esterases, allowing a more narrow therapeutic window. Trospium ER offers a once-daily option with side effect rates lower than those of a previously approved and efficacious drug. Trospium is a hydrophilic, quaternary amine with limited ability to cross the blood-brain barrier. This, in theory at least, should result in minimal cognitive-related dysfunction [43]. Contraindications for all of these drugs include uncontrolled narrow-angle glaucoma, urinary retention, gastric retention, or conditions with severely decreased gastrointestinal motility. Determining where these three new antimuscarinic options fit among the other available drugs in the same class is a challenge as head-to-head trials resulting in comparative efficacies of these agents have not been performed. As more clinical experience is reported for drugs like PDE inhibitors and BTX for the treatment of $\mathrm{OAB}$, more practitioners are becoming comfortable offering off-label use of these agents, thus providing an alternative to antimuscarinic treatment. Despite the great interest and vast number of research studies focusing on $\mathrm{OAB}$, few novel pharmaceutical agents have made it to market, and with the exception of BTX, there have been few surgical innovations for the treatment of OAB. The use of expanded indications (including patients with neurologic disease) and additional implantation routes have resulted in the successful treatment of countless refractory $\mathrm{OAB}$ patients with neuromodulation over the last couple of years. Neuromodulation is considered ineffective and thus contraindicated in patients with complete spinal cord injury.

Ongoing scientific research has provided us with greater sophistication and a clearer understanding of the mechanisms of therapeutic interventions for $\mathrm{OAB}$ and this should inevitably translate to more refined and directed therapies in the future. There are several classes of drug currently in phase II and phase III testing which may have a great impact on the treatment of $\mathrm{OAB}$ in upcoming years.

\section{Abbreviations}

5-HMT, 5-hydroxymethyl tolterodine; AR, adrenergic receptor; BTX, botulinum toxin; CAMP, cyclic adenosine monophosphate; cGMP, cyclic guanosine monophosphate; CIC, clean intermittent catheterization; $\mathrm{ED}$, erectile dysfunction; ER, extended release; HRQoL, health-related quality of life; IPSS, International Prostate Symptom Score; IR, immediate release; LUT, lower urinary tract; $\mathrm{OAB}$, overactive bladder; $\mathrm{OXY}$, oxybutynin; PDE, phosphodiesterase; PTNS, percutaneous tibial nerve stimulation; PVR, post-void residual; RCT, randomized control trial; SNM, sacral neuromodulation; $\mathrm{U}$, units; UI, urinary incontinence.

\section{Competing interests}

ALS declares that she has no competing interests. AJW is an advisor for Astellas (Tokyo, Japan), Novartis (Basel, Switzerland), Pfizer Inc. (New York, NY, USA), and Endo Pharmaceuticals (Newark, DE, USA).

\section{References}

I. Cartwright R, Cardozo L: Transdermal oxybutynin: sticking to the facts. Eur Urol 2007, 51 :907-I4.

2. Abrams P, Cardozo L, Fall M, Griffiths D, Rosier P, Ulmsten U, van Kerrebroeck P, Victor A, Wein A; Standardisation SubCommittee of the International Continence Society: The standardisation of terminology of lower urinary tract function: report from the standarisation sub-committee of the International Continence Society. Neurourol Urodyn 2002, 21 : 167-78.

3. Chapple CR, Khullar V, Gabriel Z, Muston D, Bitoun CE, Weinstein $D$ : The effects of antimuscarinic treatments in overactive bladder: an update of a systematic review and meta-analysis. Eur Urol 2008, 54:543-62.

4. Andersson KE: New pharmacologic targets for the treatment of the overactive bladder: an update. Urology 2004, 63(Suppl 3A):32-4I.

5. Staskin DR, Dmochowski RR, Sand PK, Macdiarmid SA, Caramelli KE, Thomas H, Hoel G: Efficacy and safety of oxybutynin chloride topical gel for overactive bladder: a randomized, 
double-blind, placebo controlled, multicenter study. J Urol 2009, 18I:1764-72

6. Chapple C, Van Kerrebroeck P, Tubaro A, Haag-Molkenteller C, Forst HT, Massow U, Wang J, Brodsky M: Clinical efficacy, safety, and tolerability of once-daily fesoterodine in subjects with overactive bladder. Eur Urol 2007, 52:1204-12.

7. Michel MC: Fesoterodine: a novel muscarinic receptor antagonist for the treatment of overactive bladder syndrome. Expert Opin Pharmacother 2008, 9:1787-96.

8. Khullar V, Rovner ES, Dmochowski R, Nitti V, Wang J, Guan Z: Fesoterodine dose response in subjects with overactive bladder syndrome. Urology 2008, 71:839-43.

9. Staskin D, Sand P, Zinner N, Dmochowski R; Trospium Study Group: Once daily trospium chloride is effective and well tolerated for the treatment of overactive bladder: results from a multicenter phase III trial. J Urol 2007, 178(3 Pt I):978-83.

10. Dmochowski RR, Sand PK, Zinner NR, Staskin DR: Trospium $60 \mathrm{mg}$ once daily (QD) for overactive bladder syndrome: results from a placebo-controlled interventional study. Urology 2008, $71: 449-54$.

1I. MacDiarmid S, Sandage BW Jr, Malhotra BK: The effects of reformulation: improved therapeutic index. Curr Urol Rep 2008, 9:465-7I.

12. Nomiya M, Yamaguchi O: A quantitative analysis of mRNA expression of alpha $I$ and beta-adrenoceptor subtypes and their functional roles in human normal and obstructed bladders. J Urol 2003, I 70(2 Pt I):649-53.

13. Michel MC, Vrydag W: Alpha I-, alpha2- and beta-adrenoceptors in the urinary bladder, urethra and prostate. $\mathrm{Br} J$ Pharmacol 2006, I47(Suppl 2):S88-II9.

14. Woods M, Carson N, Norton NW, Sheldon JH, Argentieri TM: Efficacy of the beta3-adrenergic receptor agonist CL-3 I6243 on experimental bladder hyperreflexia and detrusor instability in the rat. J Urol 200 I, 166:1 I42-7.

15. Wein AJ, Levin RM, Barrett DM: Voiding function: relevant anatomy, physiology, and pharmacology. In Adult and Pediatric Urology. Edited by Duckett JW, Howards ST, Grayhack JT, Gillenwater JY. St. Louis, MO: Mosby; 1991:933-99.16.

16. Chapple CR, Yamaguchi O, Ridder A, Liehne J, Carl S, Mattiasson A, Aramburu MAL, Lucas M, Everaert K: Clinical proof of concept study (Blossom) shows novel b3 andrenoceptor agonist YMI78 is effective and well tolerated in the treatment of symptoms of overactive bladder. Eur Urol Suppl 2007, 7:239. Abstract 674

17. Sairam K, Kulinskaya E, McNicholas TA, Boustead GB, Hanbury DC: Sildenafil influences lower urinary tract symptoms. BJU Int 2002, 90:836-9.

18. Andersson KE: Pathways for relaxation of detrusor smooth muscle. Adv Exp Med Bio 1999, 462:241-52.

19. McVary KT, Monnig W, Camps JL Jr, Young JM, Tseng LJ, van den Ende G: Sildenafil citrate improves erectile function and urinary symptoms in men with erectile dysfunction and lower urinary tract symptoms associated with benign prostatic hyperplasia: a randomized, double-blind trial. J Urol 2007, I77: $107 \mid-7$

FI000 Factor 3.0 Recommended

Evaluated by Chris McMahon 13 Mar 2007

20. Datta SN, Kavia RB, Gonzales G, Fowler C]: Results of doubleblind placebo-controlled crossover study of sildenafil citrate (Viagra) in women suffering from obstructed voiding or retention associated with the primary disorder of sphincter relaxation (Fowler's Syndrome). Eur Urol 2007, 51 1:495-7.

21. McVary KT, Roehrborn CG, Kaminetsky JC, Auerbach SM, Wachs B, Young JM, Esler A, Sides GD, Denes BS: Tadalafil relieves lower urinary tract symptoms secondary to benign prostatic hyperplasia. J Urol 2007, I77:140I-7.

22. Stief CG, Porst $H$, Neuser D, Beneke M, Ulbrich E: A randomised, placebo-controlled study to assess the efficacy of twice-daily vardenafil in the treatment of lower urinary tract symptoms secondary to benign prostatic hyperplasia. Eur Urol 2008, 53:1236-44.

FI000 Factor 3.0 Recommended

Evaluated by Stavros Gravas 19 Sep 2008

23. Truss MC, Stief CG, Uckert S, Becker AJ, Wefer J, Schultheiss D, Jonas U: Phosphodiesterase I inhibition in the treatment of lower urinary tract dysfunction: from bench to bedside. World J Urol 200I, 19:344-50.

24. Schurch B, Schmid DM, Stöhrer M: Treatment of neurogenic incontinence with botulinum toxin A. N Engl J Med 2000, 342:665.

25. Dmochowski R, Sand PK: Botulinum toxin A in the overactive bladder: current status and future directions. BJU Int 2007, 99:247-62.

26. Kalsi V, Gonzales G, Popat R, Apostolidis A, Elneil S, Dasgupta P, Fowler CJ: Botulinum injections for the treatment of bladder symptoms of multiple sclerosis. Ann Neurol 2007, 62:452-7.

27. Reitz A, Denys P, Fermanian C, Schurch B, Comperat E, ChartierKastler E: Do repeat intradetrusor botulinum toxin type a injections yield valuable results? Clinical and urodynamic results after five injections in patients with neurogenic detrusor overactivity. Eur Urol 2007, 52:1729-35.

28. Sahai A, Khan MS, Dasgupta P: Efficacy of botulinum toxin-A for treating idiopathic detrusor overactivity: results from a single center, randomized, double-blind, placebo controlled trial. J Urol 2007, 177:223I-6.

29. Brubaker L, Richter HE, Visco A, Mahajan S, Nygaard I, Braun TM, Barber MD, Menefee S, Schaffer J, Weber AM, Wei J; Pelvic Floor Disorders Network: Refractory idiopathic urge urinary incontinence and botulinum A injection. J Urol 2008, 180:2 17-22.

30. Schmid D, Sauermann P, Werner M, Schuessler B, Blick N, Muentener M, Strebel RT, Perucchini D, Scheiner D, Schaer G, John H, Reitz A, Hauri D, Schurch B: Experience with 100 cases treated with botulinum-A toxin injections in the detrusor muscle for idiopathic overactive bladder syndrome refractory to anticholinergics. J Urol 2006, 176:177-85.

3I. Fowler CJ, Swinn MJ, Goodwin RJ, Oliver S, Craggs M: Studies of the latency of pelvic floor contraction during peripheral nerve evaluation show that the muscle response is reflexly mediated. J Urol 2000, 163:88I-3.

32. Kessler TM, Fowler C]: Sacral neuromodulation for urinary retention. Nat Clin Pract Urol 2008, 5:657-66.

33. Wallace PA, Lane FL, Noblett KL: Sacral nerve neuromodulation in patients with underlying neurologic disease. Am J Obstet Gynecol 2007, 197:96.el-5.

34. Lombardi G, Del Popolo G: Clinical outcome of sacral neuromodulation in incomplete spinal cord injured patients suffering from neurogenic lower urinary tract symptoms. Spinal Cord 2009, 47:486-91.

35. Peters KM, Macdiarmid SA, Wooldridge LS, Leong FC, Shobeiri SA, Rovner ES, Siegel SW, Tate SB, Jarnagin BK, Rosenblatt PL, Feagins BA: Randomized trial of percutaneous tibial nerve stimulation versus extended-release tolterodine: results from the overactive bladder innovative therapy trial. J Urol 2009, 182: |055-6|.

FI000 Factor 3.0 Recommended Evaluated by JLH Ruud Bosch 05 Jan 2010

36. Govier FE, Litwiller S, Nitti V, Kreder KJ Jr, Rosenblatt P: Percutaneous afferent neuromodulation for the refractory overactive bladder: results of a multicenter study. J Urol 200I, 165:1193.

37. Spinelli M, Malaguti S, Giardiello G, Lazzeri M, Tarantola J, Van Den Hombergh U: A new minimally invasive procedure for pudendal nerve stimulation to treat neurogenic bladder: description of the method and preliminary data. Neurourol Urodyn 2005, 24:305-9. 
38. Peters KM, Killinger KA, Boguslawski BM, Boura JA: Chronic pudendal neuromodulation: expanding available treatment options for refractory urologic symptoms. Neurourol Urodyn 2009, [Epub ahead of print].

39. Peters KM, Feber KM, Bennett RC: Sacral versus pudendal nerve stimulation for voiding dysfunction: a prospective, singleblinded, randomized, crossover trial. Neurourol Urodyn 2005, 24:643-7.

40. Andersson KE, Wein AJ: Pharmacologic management of storage and emptying failure In Campbell-Walsh Urology. Edited by Wein AJ, Kavoussi LR, Novick AC, Partin AW, Peters CA. Philadelphia: Saunders; 2007:209I-123.
4I. Andersson KE, Chapple CR, Cardozo L, Cruz F, Hashim H, Michel MC, Tannenbaum C, Wein AJ: Pharmacological treatment of urinary incontinence. In Incontinence. Edited by Abrams P, Cardozo L, Khoury S, Wein AJ. Paris: Health Publication Ltd; 2009:63I-99.

42. Malhotra B, Gandelman K, Sachse R, Wood N, Michel MC: The design and development of fesoterodine as a prodrug of 5-hydroxymethyl tolterodine (5-HMT), the active metabolite of tolterodine. Curr Med Chem 2009, 16:448I-9.

43. Todorova A, Vonderheid-Guth B, Dimpfel W: Effects of tolterodine, trospium chloride, and oxybutynin on the central nervous system. J Clin Pharmacol 200I, 4I:636-44. 